\title{
Inhibition of Proline Utilization by Glutamate during Steady-state Growth of Saccharomyces cerevisiae
}

\author{
By T. G. WATSON \\ National Food Research Institute, \\ Council for Scientific and Industrial Research, P.O. Box 395, \\ Pretoria, Ooor, Republic of South Africa
}

(Received I8 April 1977; revised 4 July 1977)

Proline utilization during growth of Saccharomyces cerevisiae is inhibited by the presence of other amino acids. Steady-state simultaneous utilization of proline and glutamate is possible, however, in a nitrogen-limited continuous culture. A switch to steady-state inhibition of proline utilization may be effected by a change in growth rate. Under the conditions studied, inhibition occurred on the catabolic route from proline to glutamate and was not mediated through the concentration of pool amino acids. In batch culture, the control site was shifted to proline permease by increasing the extracellular concentration of glutamate.

\section{INTRODUCTION}

Proline utilization is inhibited in strains of Saccharomyces cerevisiae and Saccharomyces uvarum during growth in the presence of other amino acids (Jones \& Pierce, I964). Schwencke \& Magaña-Schwencke (I969) and Kuznar, Schwencke \& Magaña-Schwencke (1973) have demonstrated the existence of a proline transport system in Saccharomyces chevalieri which is repressed in cells grown in complex medium or in synthetic medium containing $\left(\mathrm{NH}_{4}\right)_{2} \mathrm{SO}_{4}$ as sole nitrogen source. Derepression of the transport system occurs during nitrogen starvation. The effect does not appear to be one of transinhibition since neither preloading the cells with proline nor replenishment of the total amino-acid pool during starvation inhibits subsequent uptake. Furthermore, other amino acids, which are thought to be subject to transinhibition, show a completely different time-course variation in nitrogenstarvation conditions. They conclude that the transport of proline is regulated at the level of protein biosynthesis. Lundgren \& Ogur (1973) observed that a number of common amino acids inhibited the growth of a yeast glutamate auxotroph on proline. They suggested that the size of the amino-acid pool controls glutamate formation from proline by inhibiting an enzyme in the catabolic pathway, $\Delta^{1}$-pyrroline-5-carboxylate dehydrogenase, and that this is the principal regulatory mechanism for the failure of growth.

In this paper, I report a switch from steady-state simultaneous utilization of proline and glutamate to steady-state inhibition of proline utilization by glutamate, effected by a change of growth rate, in a nitrogen-limited continuous culture of $S$. cerevisiae.

\section{METHODS}

The organism used was Saccharomyces cerevisiae Y48 from the culture collection of the Microbiology Research Group of the South African Council for Scientific and Industrial Research, Pretoria.

Details of the basal growth medium, batch and continuous culture techniques, determination of yeast dry weights and amino-acid pools have been described previously (Watson, 1976). Extracellular proline concentrations were measured using step 4 of the method of Wren \& Wiggall (1965). 
Table I. Amino-acid pool composition of Saccharomyces cerevisiae grown in a nitrogen-limited (I mM-glutamate plus I mM-proline) continuous culture at various dilution rates

Pool amino acid $[\mu \mathrm{mol}$ (IOO $\mathrm{mg}$ dry wt $\left.)^{-1}\right]$

Alanine
Arginine
Asparagine
Aspartic acid
Citrulline
Cysteine
Glutamic acid
Glutamine
Glycine
Histidine
Isoleucine
Leucine
Lysine
Methionine
Ornithine
Phenylalanine
Proline
Serine
Threonine
Tryptophan
Tyrosine
Valine
Total
No of determinations

\begin{tabular}{|c|c|c|c|c|}
\hline \multicolumn{5}{|c|}{ Dilution rate $\left(\mathrm{h}^{-1}\right)$} \\
\hline 0.04 & 0.10 & 0.21 & 0.30 & 0.35 \\
\hline 0.43 & 0.79 & $I \cdot 34$ & $2 \cdot 34$ & $2 \cdot 30$ \\
\hline 0.08 & 0.15 & $\mathrm{I} \cdot 4 \mathrm{I}$ & $7 \cdot 26$ & $7 \cdot 89$ \\
\hline 0.10 & 0.12 & - & - & 一 \\
\hline 0.62 & 0.83 & 0.72 & 0.49 & 0.45 \\
\hline$\longrightarrow$ & - & 0.08 & $0.8 \mathrm{I}$ & $I \cdot 7 I$ \\
\hline 一 & 0.18 & 一 & 一 & - \\
\hline $2 \cdot 87$ & $5 \cdot 84$ & I 5.44 & $20 \cdot 70$ & $2 I \cdot 39$ \\
\hline 0.23 & $0.4 \mathrm{I}$ & $2 \cdot 36$ & 6.63 & 9.06 \\
\hline 0.13 & 0.10 & 0.24 & 0.54 & 0.89 \\
\hline 0.06 & 一 & 0.15 & 0.36 & 0.45 \\
\hline O.I I & 0.07 & 0.08 & 0.12 & 0.18 \\
\hline $0.2 \mathrm{I}$ & 0.12 & 0.15 & 0.20 & 0.25 \\
\hline 0.12 & 0.09 & 0.38 & 0.44 & 0.64 \\
\hline 0.07 & 一 & 0.15 & - & - \\
\hline 0.08 & $0.1 \mathrm{I}$ & 0.28 & 0.44 & $I \cdot 73$ \\
\hline 0.13 & 0.08 & 0.07 & 0.12 & - \\
\hline O. I I & 0.13 & $1 \cdot 73$ & $7 \cdot 95$ & $6 \cdot 23$ \\
\hline 0.20 & 0.23 & 0.73 & $\mathrm{I} \cdot 40$ & $2 \cdot 43$ \\
\hline 0.14 & $0 \cdot 14$ & 0.33 & 0.63 & 0.53 \\
\hline- & 0.05 & 0.32 & $I \cdot 70$ & $I \cdot 58$ \\
\hline 0.09 & 0.05 & - & 0.08 & 0.09 \\
\hline 0.24 & 0.16 & 0.44 & 0.50 & 0.62 \\
\hline $6 \cdot 02$ & $9 \cdot 65$ & $26 \cdot 40$ & $52 \cdot 7 \mathrm{I}$ & $58 \cdot 42$ \\
\hline 3 & 2 & 4 & 3 & 2 \\
\hline
\end{tabular}

-, Concentration less than $0.05 \mu \mathrm{mol}(100 \mathrm{mg} \text { dry wt })^{-1}$.

Steady-state amino-acid uptake rates in continuous culture were calculated as follows:

$$
\text { Uptake rate } \left.[\mu \mathrm{mol} \text { (100 mg dry wt yeast })^{-1} \mathrm{~h}^{-1}\right]=\frac{\mathrm{IOO}\left(S_{\mathrm{R}}-S\right) \mu}{x}
$$

where $S_{\mathrm{R}}$ is the amino-acid concentration (mM) in the inflowing medium; $S$, the amino-acid concentration within (and leaving) the culture vessel; $x$, the density of yeast in the culture vessel (mg dry wt $\mathrm{ml}^{-1}$ ); and $\mu$, the specific growth rate $\left(\mathrm{h}^{-1}\right)$, which is equal to $D$, the dilution rate, under steady-state conditions.

\section{RESULTS AND DISCUSSION}

Saccharomyces cerevisiae grown in a nitrogen-limited continuous culture containing I mM-glutamate plus I mM-proline as sole nitrogen source, utilized both amino acids simultaneously with only traces remaining in the culture medium at dilution rates below $0.30 \mathrm{~h}^{-1}$. When $D$ was increased to $0.35 \mathrm{~h}^{-1}$, however, proline utilization was inhibited severely (Fig. I) and $90 \%$ of the proline supplied to the culture was unused.

When $D$ was increased from $0.30 \mathrm{~h}^{-1}$ to $0.35 \mathrm{~h}^{-1}$ the total pool of amino acids was only slightly raised (Table I). The inhibitory effect observed is, therefore, not mediated through the total concentration of the amino-acid pool or its individual components.

At dilution rates below $0.30 \mathrm{~h}^{-1}$, the proline uptake rate correlated with the intracellular proline concentration (Fig. 2). Since the level of proline in the amino-acid pool does not drop appreciably as a result of inhibition of utilization, the principal site of inhibition probably occurs on the catabolic route from proline to glutamate. A lowering of the transport activity must also be inferred, however, otherwise presumably the proline pool would have become larger when the extracellular concentration of proline was increased. As a possible form of control, in the absence of evidence to support amino-acid pool participation, an aminoacyl-tRNA has been proposed to regulate proline oxidase in Escherichia coli (Deutch \& Soffer, 1975). 


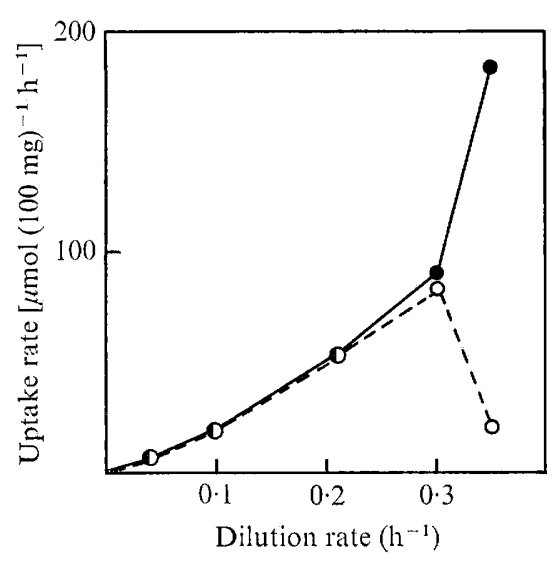

Fig. I

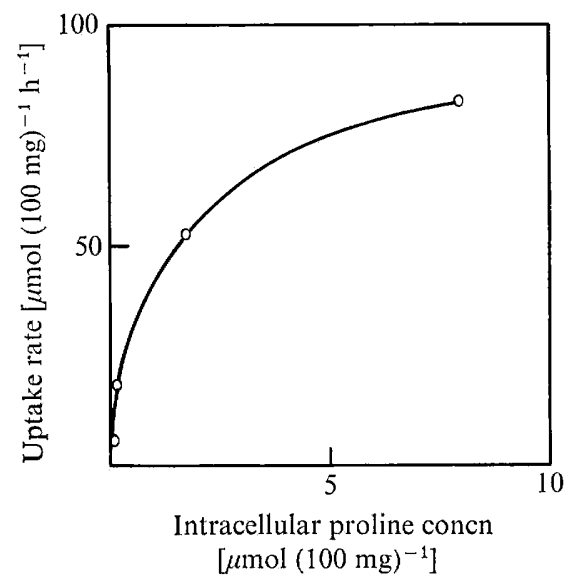

Fig. 2

Fig. I. Steady-state glutamate $(O)$ and proline $(O)$ uptake rates in a nitrogen-limited (I mMglutamate plus I mM-proline) continuous culture of $S$. cerevisiae.

Fig. 2. Relation between steady-state proline uptake rate and intracellular proline concentration in a nitrogen-limited (I mM-glutamate plus I mM-proline) continuous culture of $S$. cerevisiae below a dilution rate of $0.30 \mathrm{~h}^{-1}$.

Table 2. Uptake and intracellular accumulation of proline by Saccharomyces cerevisiae grown on various media in batch culture and harvested during early-exponential growth

\begin{tabular}{|c|c|c|c|c|}
\hline & \multicolumn{4}{|c|}{ Nitrogen source in basal medium } \\
\hline & Glu (2 mM) & Pro (2 mM) & $\begin{array}{l}\text { Glu }(2 \mathrm{~mm})+ \\
\text { Pro }(2 \mathrm{~mm})\end{array}$ & $\begin{array}{l}\text { Glu (Io mM) }+ \\
\text { Pro }(2 \mathrm{~mm})\end{array}$ \\
\hline $\begin{array}{l}\text { Intracellular proline concn } \\
{\left[\mu \mathrm{mol}(\mathrm{r} 00 \mathrm{mg} \text { dry } \mathrm{wt})^{-1}\right]}\end{array}$ & $I \cdot 70$ & II $\cdot 47$ & $7 \cdot 24$ & $2 \cdot 08$ \\
\hline $\begin{array}{l}\text { Extracellular proline concn } \\
(\mathrm{mM}) \text { at harvest }\end{array}$ & - & $I \cdot I 6$ & $I \cdot 90$ & $I \cdot 99$ \\
\hline $\begin{array}{l}\text { Cell concn (mg dry wt } \mathrm{ml}^{-1} \text { ) } \\
\text { at harvest }\end{array}$ & 0.15 & 0.13 & $0 \cdot 13$ & $0 \cdot 16$ \\
\hline $\begin{array}{l}\text { Specific growth rate }\left(\mathrm{h}^{-1}\right) \text { at } \\
\text { harvest }\end{array}$ & 0.38 & 0.22 & 0.38 & 0.38 \\
\hline
\end{tabular}

In ancillary experiments, yeast cells grown batchwise, in basal medium containing 2 mM-proline plus 2 mM-glutamate and harvested during early-exponential growth at an extracellular glutamate concentration of $0.7 \mathrm{~mm}$, responded similarly to those grown in continuous culture under conditions of inhibition of proline utilization $\left(D=0.35 \mathrm{~h}^{-1}\right)$ at an extracellular glutamate concentration of approximately $0.2 \mathrm{mM}$. That is, although showing poor utilization of proline, they did accumulate proline intracellularly (Table 2). When the glutamate concentration of the basal medium was increased to ro $\mathrm{mm}$, the proline concentration in the intracellular pool of the cells was the same as in a control grown on glutamate alone (Table 2), indicating, in the absence of proline utilization, loss of transport activity. The principal control site is thus shifted from the proline catabolic pathway to the proline permease in response to a higher concentration of glutamate.

I am grateful to Celia Hollingworth, Ilze Meyer, Doreen Morgan and L. Pretorius for valuable technical assistance. 


\section{REFERENCES}

DeUTCH, C. E. \& SofFer, R. L. (I975). Regulation of proline catabolism by leucyl, phenylalanyl-tRNAprotein transferase. Proceedings of the National Academy of Sciences of the United States of America 72, 405-408.

JoNES, M. \& PIERCE, J. S. (1964). Absorption of amino acids from wort by yeasts. Journal of the Institute of Brewing 70, 307-315.

KuZnar, J., Schwencke, J. \& MAGAÑa-SChwencKe, N. (1973). Sarcosine and imino acid uptake in Saccharomyces chevalieri. Biochimica et biophysica acta 318, 273-280.

LuNDGREN, D. W. \& OGuR, M. (1973). Inhibition of yeast $\Delta^{1}$-pyrroline-5-carboxylate dehydrogenase by common amino acids and the regulation of pro- line catabolism. Biochimica et biophysica acta $\mathbf{2 9 7}$, 246-257.

SChwencke, J. \& Magaña-Schwencke, N. (I 969 ). Derepression of a proline transport system in Saccharomyces chevalieri by nitrogen starvation. Biochimica et biophysica acta 173, 302-31 2.

WATson, T. G. (1976). Amino-acid pool composition of Saccharomyces cerevisiae as a function of growth rate and amino-acid nitrogen source. Journal of General Microbiology 96, 263-268.

Wren, J. J. \& WigGall, P. H. (I965). An improved colorimetric method for the determination of proline in the presence of other ninhydrin-positive compounds. Biochemical Journal 94, 2 I 6-220. 